\title{
Editorial: Assessment and Modeling of Soil Functions or Soil-Based Ecosystem Services: Theory and Applications to Practical Problems
}

\author{
Philippe C. Baveye ${ }^{1 \star}$, Estelle Dominati ${ }^{2}$, Adrienne Grêt-Regamey ${ }^{3}$ and Hans-Jörg Vogel ${ }^{4}$ \\ ${ }^{1}$ Saint Loup Research Institute, Saint Loup Lamairé, France, ${ }^{2}$ AgResearch Ltd., Hamilton, New Zealand, ${ }^{3}$ Institut für Raum- und \\ Landschaftsentwicklung (IRL), ETH Zurich, Zurich, Switzerland, ${ }^{4}$ Helmholtz Centre for Environmental Research - UFZ, Leipzig, \\ Germany
}

Keywords: ecosystem services, human, populations, soil preservation, soil degradation

\author{
Editorial on the Research Topic
}

Assessment and Modeling of Soil Functions or Soil-Based Ecosystem Services: Theory and Applications to Practical Problems

In the soil-related literature of the past half-century, two different perspectives have been adopted to deal with the benefits that are provided by soils (Baveye et al., 2016). The first perspective, initiated in the mid1960s, centres on the multiple "functions" of soils, defined as the benefits that not just human populations, but also the rest of nature derive from soils. Simonson (1966) used the term of "multifunctionality" to stress the fact that these functions are numerous, and are often fulfilled simultaneously. Decision-makers quickly adopted this perspective; as early as 1972, the Council of Europe used it in some of its official documents related to the preservation of soil resources. Implementation of some of the guidelines that have resulted has been greatly facilitated by the elaboration by Blum (1988) of a detailed classification of soil functions (illustrated in Figure 1) and, slightly later, by the FAO of a similar, but more complete one. Both classifications have proven to be very useful communication tools to explain to lay audiences, in simple terms, what soils contribute to nature, and in particular to human populations, and therefore how vital it is to prevent their degradation. A second perspective, largely inspired by the sizeable intellectual achievement of the Millenium Ecosystem Assessment (Millennium Ecosystem Assessment, 2005), focuses on the contributions that soils make to "ecosystem services", i.e., the benefits that human populations derive from ecosystems encompassing soils.

Uncertainties and controversies resulting from the terminology in use have been associated with the concept of ecosystem services from the start (e.g., Barnaud and Antona, 2014). In the case of soils, the existence of two distinct traditions, one firmly rooted in soil science, and the other inherited from ecology, has in the last few years caused some level of confusion, because different terms are sometimes used to denote different concepts. In particular, from the soil science perspective, services, i.e., benefits that human populations derive from soils, correspond to a subset of soil functions, which by definition are not restricted to human populations. However, from the ecological perspective, the term of "function" has been traditionally associated with the physical (bio)chemical, or biological processes occurring in ecosystems that give rise to ecosystem services, and that same acception of the term has occasionally also been adopted by soil scientists (see, e.g., Keesstra et al., 2016; Pereira et al., 2018). In addition, some authors (e.g., in Issue 184 of the Philosophical Transactions of the Royal Society B, devoted in September 2021 to the topic) have also started to use the alternative expression of "nature's contribution to people" instead of ecosystem services, which adds even more to confusion, since the difference between these different terms is not obvious (Braat, 2018; Baveye et al., 2018). 


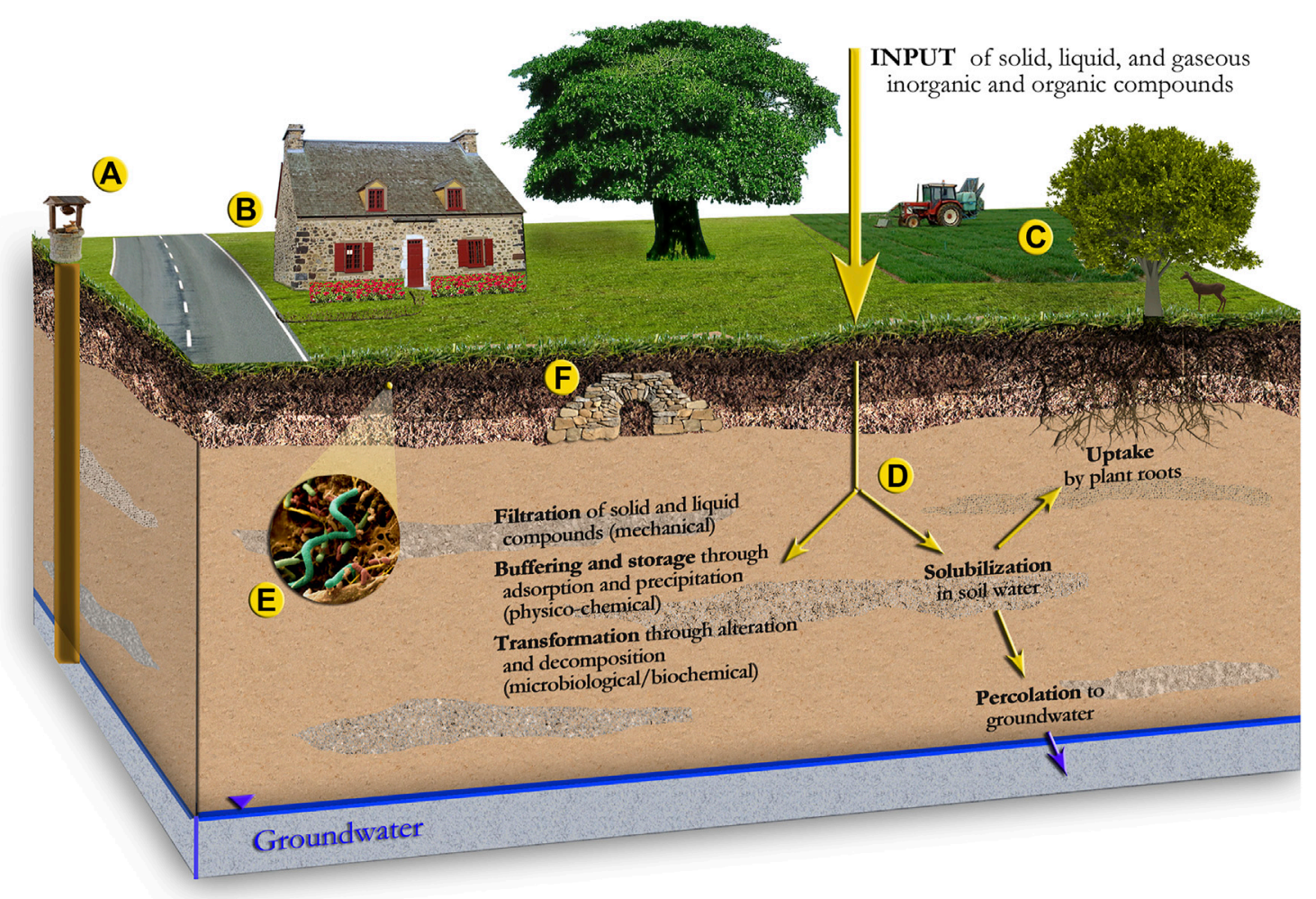

FIGURE 1 | Schematic illustration of the different functions of soils according to Blum (1988) classification. The six categories of soil functions correspond, respectively, to (A) the extraction of raw materials and water, (B) physically supporting buildings and other man-made structures, (C) the production of biomass, (D) filtration, buffering, storage, and chemical/biochemical transformations, and (E) the preservation of biodiversity or potentially useful genetic material, as well as of geogenic and cultural heritage (F)

Regardless of the perspective that is adopted, i.e., whether we consider only the benefits of soils to human populations or we look more broadly at the benefits to nature as a whole, the hope existed 3 years ago, when we started thinking about proposing a Research Topic in the area, that soil functions/services could be used in practice in decision-making affecting the fate of soil resources. Unfortunately, in this respect, a significant hurdle at the time related to the lack of quantitative assessment of soil functions/ services and of their provision under different land uses (Baveye, 2017). In the scientific literature up to that time, there were virtually no direct measurements of multiple soil functions or services at spatial and temporal scales of practical relevance. Soil functions/services tended to be estimated, rather than measured, using proxy variables or indicator parameters, leading eventually to maps of soil functions, a number of which have been produced over the last few years. An alternative assessment method relied on modelling, in which in addition to statistical correlations (e.g., pedotransfer functions), detailed process understanding could be explicitly accounted for. Modelling could in principle help us move beyond the mere quantification of functions/services at a given instant, and quantify the temporal dynamics of soil functions/ services (e.g., in response to external forcing), but the approach was in dire need of verification.
To help strengthen the literature in this crucial area, the objective of the Research Topic we proposed was to serve as an outlet for articles that dealt with any aspect of the simultaneous assessment of multiple soil functions and their contributions to the provision of ecosystem services, from a conceptual standpoint, from the perspective of the development of new methodologies, or from the angle of practical applications to concrete problems and implementation for decision making about land use or land management change. Contributions on the concrete, practical side were particularly welcome, as were also papers that dealt with some of the soil functions and soilbased ecosystem services that are less frequently assessed, let alone discussed, for example the preservation of cultural artefacts, or the role of soils as stock of genetic information (e.g., in the development of antibiotics or phage therapy).

Eleven articles were eventually accepted for publication in this Research Topic. Three articles, by Vogel et al., Mikhailova et al., Gerard et al., and Lennartz and Liu, deal with different aspects of the assessment of soil functions/services. Although peripherally related to soil functions/services, the article by George et al. shows that fungal biodiversity, one of several soil biodiversity parameters that are often associated with the delivery of soil functions/services, can be measured in very different ways, potentially leading to ambiguity. 
Rioux et al. address the mapping of soil functions/services, whereas Mikhailova et al. and Cope et al. also discuss the possible monetary evaluation of soil functions/services. A second group of articles focuses on modelling of soil functions/services using different approaches, including proxy parameters (Fossey et al., Van Leeuwen et al.), and three present Decision Support tools meant to facilitate the involvement of soil functions/services in practical soil management situations (Sandén et al., Debeljak et al., Van de Broek et al.).

Thanks in part to the work of the authors who contributed to this Research Topic, but also to research carried out in parallel (Chalhoub et al., 2020; Choquet et al., 2021), significant progress has been achieved recently on the measurement of soil functions/ services, and on the development of various modelling frameworks to predict them in practical situations. Nevertheless, if we want the soil functions/services framework to become a useful tool for the preservation of soils in practice, it seems clear that in the next few years, the soil science community will have to devote even more attention to the methods used to assess and model soil functions, and will have to find ways to facilitate this assessment in practical applications to increase the use of relevant information for decision-making. The need is likely to become particularly acute in this area for three key reasons. The first is that climate change is forecasted to lead to pressures on soils that they have not experienced so far, e.g., in terms of regulation of the water regime under significantly more intense and less frequent rainfalls (see discussion in Baveye et al., 2020). A second reason is that at the European level the common

\section{REFERENCES}

Barnaud, C., and Antona, M. (2014). Deconstructing Ecosystem Services: Uncertainties and Controversies Around a Socially Constructed Concept. Geoforum 56, 113-123. doi:10.1016/j.geoforum.2014.07.003

Baveye, P. C., Baveye, J., and Gowdy, J. (2016). Soil "Ecosystem" Services and Natural Capital: Critical Appraisal of Research on Uncertain Ground. Front. Environ. Sci. 4, 41. doi:10.3389/fenvs.2016.00041

Baveye, P. C., Chalhoub, M., Choquet, P., and Montagne, D. (2018). Is the Focus on "Ecosystems" a Liability in the Research on Nature's Services? Front. Ecol. Evol. 6, 226. doi:10.3389/fevo.2018.00226

Baveye, P. C. (2017). Quantification of Ecosystem Services: Beyond All the "Guesstimates", How Do We Get Real Data? Ecosystem Serv. 24, 47-49. doi:10.1016/j.ecoser.2017.02.006

Baveye, P. C., Schnee, L. S., Boivin, P., Laba, M., and Radulovich, R. (2020). Soil Organic Matter Research and Climate Change: Merely Re-Storing Carbon Versus Restoring Soil Functions. Front. Environ. Sci. 8, 579904. doi:10.3389/ fenvs.2020.579904

Blum, W. E. H. (1988). "Problems of Soil Conservation," in Nature and Environment Series (Strasbourg: Council of Europe, Steering Committee for the Conservation and Management of the Environment and Natural Habitats CDPE), 39.

Braat, L. C. (2018). Five Reasons why the Science Publication "Assessing Nature's Contributions to People" (Diaz et al. 2018) Would Not Have Been Accepted in Ecosystem Services. Ecosystem Serv. 30, A1-A2. doi:10.1016/ j.ecoser.2018.02.002

Chalhoub, M., Gabrielle, B., Tournebize, J., Chaumont, C., Maugis, P., Girardin, C., et al. (2020). Direct Measurement of Selected Soil Services in a Drained Agricultural Field: Methodology Development and Case Study in Saclay (France). Ecosystem Serv. 42, 101088. doi:10.1016/j.ecoser.2020.101088

Choquet, P., Gabrielle, B., Chalhoub, M., Michelin, J., Sauzet, O., Scammacca, O., et al. (2021). Comparison of Empirical and Process-Based Modelling to agricultural policy and the subsidies it involves to agriculture will be increasingly tied to appropriate measures of sustainable land use. To enable this, quantitative instruments are needed to evaluate agricultural practices with respect to their impact on the ensemble of soil functions. A final reason is that heavy pressure of financial institutions and governments toward the development of carbon markets and carbon farming practices will raise tricky, and so far entirely unresolved, questions about what monetary value, if any, could be associated with specific soil functions/services.

We hope that the various articles in this Research Topic will, in some measure, foster a healthy dialogue on the assessment and modelling of soil functions/services, which will make it possible for the soil science community to address fruitfully the urgent questions that are being asked by society in this context.

\section{AUTHOR CONTRIBUTIONS}

All authors listed have made a substantial, direct, and intellectual contribution to the work and approved it for publication.

\section{ACKNOWLEDGMENTS}

We would like to express our sincere gratitude to the various reviewers who have volunteered their time to help the authors improve their texts.

Quantify Soil-Supported Ecosystem Services on the Saclay Plateau (France). Ecosystem Serv. 50, 101332. doi:10.1016/j.ecoser.2021.101332

Keesstra, S. D., Bouma, J., Wallinga, J., Tittonell, P., Smith, P., Cerdà, A., et al. (2016). The Significance of Soils and Soil Science towards Realization of the United Nations Sustainable Development Goals. SOIL 2, 111-128. doi:10.5194/soil-2-111-2016

Millennium Ecosystem Assessment (2005). Ecosystems and Human Well-Being. Washington, DC: Island Press.

Pereira, P., Bogunovic, I., Muñoz-Rojas, M., and Brevik, E. C. (2018). Soil Ecosystem Services, Sustainability, Valuation and Management. Curr. Opin. Environ. Sci. Health 5, 7-13. doi:10.1016/j.coesh.2017.12.003

Simonson, R. W. (1966). Shifts in the Usefulness of Soil Resources in the USA. Agriculture 23, 11-15.

Conflict of Interest: ED was employed by AgResearch Ltd.

The remaining authors declare that the research was conducted in the absence of any commercial or financial relationships that could be construed as a potential conflict of interest.

Publisher's Note: All claims expressed in this article are solely those of the authors and do not necessarily represent those of their affiliated organizations, or those of the publisher, the editors and the reviewers. Any product that may be evaluated in this article, or claim that may be made by its manufacturer, is not guaranteed or endorsed by the publisher.

Copyright (c) 2021 Baveye, Dominati, Grêt-Regamey and Vogel. This is an openaccess article distributed under the terms of the Creative Commons Attribution License (CC BY). The use, distribution or reproduction in other forums is permitted, provided the original author(s) and the copyright owner(s) are credited and that the original publication in this journal is cited, in accordance with accepted academic practice. No use, distribution or reproduction is permitted which does not comply with these terms. 